\title{
Preventive Maintenance for Mortgage Loans of Low-Income Borrowers
}

\author{
Feng $\mathrm{Xu}^{1}$, Dazhong $\mathrm{Wu}^{1}$, Jian Hua ${ }^{1} \&$ Tih Koon $\operatorname{Tan}^{1}$ \\ ${ }^{1}$ School of Business and Public Administration, University of The District of Columbia, Washington, DC, USA \\ Correspondence: Feng Xu, School of Business and Public Administration, University of The District of \\ Columbia, 4200 Connecticut Ave, NW, Washington, DC, USA. Tel: 202-274-7043.
}

Received: January 9, 2022

Accepted: February 7, 2022

Online Published: February 12, 2022

doi:10.5539/ijef.v14n3p66

URL: https://doi.org/10.5539/ijef.v14n3p66

\begin{abstract}
For borrowers with financial troubles in the mortgage market, current practice is to offer loss mitigation options only after mortgage defaults occur. Researches in this area focused on borrower's post-default options and the effectiveness of different mitigation tools and servicers' practices to prevent foreclosure. Same as researchers, practitioners and policy makers are interested mainly in determining when and how to provide interventions for delinquent loans. Some studies pointed out the cost saving effect by providing preventive services to borrowers in early delinquency stage, while others claimed the effects from altering the terms of modifying the loan contracts. In this paper, we present preventive loan maintenance models and argue that it is more cost effective by applying pre-default mitigation strategies before a borrower becomes delinquent and before the occurrence of defaults from a specific proportion of loans in a mortgage pool.
\end{abstract}

Keywords: loss mitigation, mortgage default, preventive maintenance, modulated Poisson process

\section{Introduction}

Drops of residential housing price from 2007 to mid-2012 brought significant increase of delinquencies and foreclosures of U.S. subprime mortgage loans and initiated recent financial crisis that hit the U.S. and world economy severely. Accordingly, research in studying delinquent mortgages becomes popular since 2009, with the purpose to provide effective methods for loan lenders and insurers to mitigate losses brought by mortgage defaults and potential foreclosures.

Majority of mortgage defaults do not terminate in foreclosure. Before the loss mitigation program was introduced to the residential mortgage industry in 1991, according to Gardner and Mills (1989), around 28\% of defaulted conventional mortgage borrowers finally lost their properties. Since 1991, as loss mitigation program started gaining popularity to help bring the problematic loans current, the proportion of foreclosures among defaulted loans decreased significantly. For example, Ambrose and Capone (1996) reported that about 13\% of mortgages after employing loss mitigation program would end in foreclosure. Given significant costs brought by foreclosures, the loss mitigation program is welcome by mortgage loan lenders, investors, insurers and liquidity constrained borrowers.

For residential mortgage loans, current practice in the mortgage market is to offer loss mitigation options to borrowers with financial troubles only after mortgage default occurs. Research in this area focuses on analyzing the effectiveness of different mitigation options and factors such as borrowers, servicers and investors characteristics upon the outcome of implementing loss mitigation.

In this paper, we present preventive loan maintenance models for mortgages characterized with low-income borrowers. Subprime and FHA mortgage borrowers are mainly having low household income and low creditworthiness, thus are charged higher interest rates and are offered less favorable terms. These borrowers are assumed to bear greater default risk than conventional loan borrowers. We propose that, under certain conditions, it is more cost effective by implementing proactive interventions before a borrower becomes delinquent in mortgage payment and before a specified proportion of loans in a mortgage pool default.

The rest of the paper is organized as follows. In Section 2, we briefly review loss mitigation program and relevant research in the field. Section 3 introduces preventive loan maintenance models, with empirical analysis carried out in Section 4. Section 5 concludes this research. 


\section{Loss Mitigation Programs}

Fannie Mae first introduced loss mitigation program in May 1991, by offering options and incentives to defaulted borrowers for avoiding foreclosure (Engelstad, 1991). In 1996, Freddie Mac and mortgage insurers joined the program, and the U.S. Congress empowered FHA to do the same. The program gained fast development in the U.S. mortgage industry. For example, Lipschutz (2000) reported that compared to 5,000 loss mitigation claims being processed by FHA in fiscal year (FY) 1997, the number increased to be 26,000 in FY 2000. FHA director Joseph McCloskey declared that in FY 2005, FHA paid about \$27 million incentive fees to its loan servicers for loss mitigation efforts, which helped the agency avoid losses of more than $\$ 2$ billion (National Mortgage News, Oct. 24 ${ }^{\text {th }}, 2005$ ). Although some mitigation efforts end with failures, losses of foreclosures plus additional costs incurred with the program are only a fraction of total costs of the foreclosure (Ambrose \& Capone, 1996). Stegman et al. (2007) pointed out that savings to mortgage investors and insurers when the workout program is successful are sufficient to cover the added costs of the program.

Primary, there are five loss mitigation options as foreclosure alternatives; see Stowe (1997), HUD Mortgage Letter (2000), Capone (2002) and Capone and Metz (2003) for details. These are loan modification; special forbearance such as the Mortgage Relief Programs offered during recent pandemic period; preforeclosure sales; deed-in-lieu of foreclosure; and partial claim which is only applicable to FHA loans. Alternatively, considering recent practices in loss mitigation, Agarwal et al. (2011) classified all options into four categories of liquidation, modification, repayment plans and refinancing. And they included foreclosure as one option in liquidation category.

Early research in loss mitigation area focuses on predicting post-default outcomes. For example, Ambrose and Capone (1996) proposed a model for calculating break-even success probabilities of different loss mitigation options. In another paper (Ambrose \& Capone, 1998), they presented a multinomial logistic model to predict post-default outcomes of foreclosure, reinstatement, property sale and assignment to U.S. Department of Housing and Urban Development (HUD). Ambrose and Buttimer, Jr. (2000) used a mortgage-pricing model to study the impacts of different mitigation options upon borrower's poste-default decisions. And Capone and Metz (2003) proposed a multivariate logistic regression model to test the effects of mortgage borrower and loan characteristics on success probabilities of different post-default options.

As pointed out by Ding et al. (2008), instead of focusing on borrower's post-default options, recent research shifts to analyze factors from servicers and investors side, such as better loss mitigation practices of loan servicers to prevent foreclosure. Due to deteriorating situation in the mortgage market, in Feb. 2009, the U.S. Treasury Department implemented Home Affordable Modification Program (HAMP), which is a part of Making Home Affordable Program, to help stabilize the financial market. The program provides guidelines and incentives to encourage mortgage servicers to carry out active loan modifications. Following this, many researches focuses on studying the effectiveness of modification terms and servicer practices.

Some researchers point out that reduction in monthly payment burden is effective in reducing the probability of redefault which stands for being delinquent in mortgage payment again after loan modification. White (2009) argued that the standard loan modification approach was not efficient because it was based on balloon payment, resulting in increased debt for borrowers by amortizing deferred principal, interests and fees into modified loan payments. Gerardl and Li (2010) suggested that policy makers should focus on providing assistances to borrowers who already experienced foreclosure. Agarwal et al. (2010) applied regression analysis to prove that affordability was the main reason for redefault after modifications. Considerable evidences show that modifications with reduction in principal debt relate to lower rates of redefault. Mulligan (2010) also discussed the possibility that principal reduction was more durable in preventing foreclosure. It is noted that, although majority of modifications still rely on interest reduction, term extension and capitalization of delinquent payments and fees, modifications with reduction of principal debt start to gain popularity. For example, Anderson et al. (2012) reported that the proportion of principal forgiveness within modifications increased from $5 \%$ in 2008 to be $22 \%$ in 2012.

Besides, it was suggested that more aggressive modifications should be carried out to manage redefault risk. Stegman et al. (2007) proposed "preventive servicing" which demonstrates cost saving effect from early intervention of loans being delinquent. According to their analysis, for low and moderate income delinquent borrowers, if the post-default modifications are carried out when the loans are 30 days being delinquent, only $10 \%$ of them will eventually end with foreclosure. While the practice is carried out after the loans being delinquent for more than 60 days, around 30\% of them will reach foreclosure. And for loans modified after being delinquent for at least 90 days, more than 40\% will reach foreclosure. Cutts and Merrill (2008) also claimed the effectiveness of 
default counseling for delinquent borrowers and the negative correlation between the likelihood of reinstate a loan and the length of time being delinquent. And Ding et al. (2008) pointed out that well timed counseling can effectively help delinquent borrowers to bring the loans current.

For academic researchers and practitioners as well as policy makers, the main topics of interest are to determine when and how to provide interventions for delinquent loans. Different instruments of loss mitigation have been developed to help decide how to reduce post-default costs for mortgage investors and insurers. For example, while loan modification is a commonly used loss mitigation method, multiple alternatives have being developed for loan lenders to decide whether principal reduction, interest forgiveness, term extension, etc., to be included into the modified mortgage repayment plan. For timing of carry out loss mitigation, majority of researchers focus on early intervention for post-default loans.

Fewer researches have been conducted to study pre-default mitigation strategies for managing mortgage default and foreclosure risks. Hirad and Zorn (2001) carried out empirical analysis of pre-purchase counseling for reducing mortgage default risk. And White (2009) suggested negotiating modifications before a loan becomes delinquent. As Stegman et al. (2007, p. 245) pointed out, the "key to effective and efficient preventive servicing is in knowing which borrowers to contact at which time," it can be cost effective to conduct modification and other mitigation practices for risky loans pre default to avoid significant costs brought by default and potential foreclosure. Considering mortgage lenders, investors and insurers are main bearers of default and foreclosure risks, they would benefit the most if they can determine when and which loan(s) to target at, for providing mitigations. Because of this, in this paper we propose preventive loan maintenance models, targeting at determining optimal time of carrying out loss mitigation practices towards FHA and subprime mortgage loans due to highly perceived default risks.

\section{Preventive Loan Maintenance Models}

Preventive maintenance methods are well developed and applied in survival and reliability analysis (see, e.g., Cho \& Parlar 1991; Campodonico \& Singpurwalla, 1995; Mazzuchi \& Soyer 1995; Merrick et al., 2003, 2005; Castro, 2009; Wu \& Zuo, 2010). The relationship between reliability risk and financial risk has been studied by researchers in reliability area. For example, Lynn (2004) and Singpurwalla (2007) discussed connection between financial and reliability models, and Soyer and Xu (2008) applied Bayesian models for analyzing mortgage default risks. In this section, two types of maintenance methods are provide to study the optimal time of carrying out preventive maintenances for individual mortgage loan as well as for a pool of mortgages with perceived high default risk.

\subsection{Preventive Maintenance for Individual Mortgage Loan}

FHA and subprime mortgage borrowers are more likely to have low household income, compared to conventional mortgagors. Due to perceived pressure on the affordability, prompt modification of mortgage for the borrower to maintain repayments till loan maturation, benefits both the borrower to keep the property and the lender to avoid significant costs of default and foreclosure. Therefore, the key factor for carrying out preventive maintenance practice is to determine when the loan servicer needs to negotiate with the borrower for modifying mortgage contract terms. And in this paper, we target at determining the time of providing loan modification. The detailed modification types, whether in types of principal forgiveness, interest reduction, or capitalization, are not the focus of this study.

Preventive maintenance requires precise measurements of life length, $T_{i}$, of mortgage loan $i$. Time to mortgage default is analogue to time to failure in reliability and survival analysis. Therefore, the instantaneous default rate at time $t$ of loan $i$ can be defined as,

$$
\lambda_{i}(t)=\frac{f_{i}(t)}{S_{i}(t)}
$$

In (1), $f_{i}(t)$ and $S_{i}(t)$ are probability density function and survival function of $T_{i}$, where

$$
S_{i}(t)=P\left(T_{i}>t\right)=\exp \left[-\Lambda_{i}(t)\right]
$$

and $\Lambda_{i}(t)=\int_{0}^{t} \lambda_{i}(u) d u$ is the cumulative default rate. In modeling the default rate which depends on the age of the loan, Bhattacharya et al. (2019) constructed a Bayesian lognormal competing risks model to describe default and prepayment risks together. In this study since the focus is on the default risk only, we use the commonly applied Weibull hazard rate suggested by Lambrecht et al (1997) and assume that $\lambda_{\mathrm{i}}(t)$ takes the form of

$$
\lambda_{i}(t)=\alpha \gamma t^{\gamma-1}
$$

where $\alpha, \gamma>0$ and value of $\gamma>(<) 1$ implies whether the default rate will increase or decrease over time. 
Besides loan age, mortgage default risk is also determined by some covariates influencing the equity value and ability-to-pay of the borrower. To incorporate covariates into the model, a proportional hazards model (PHM) format of Cox (1972) can be applied, with the default rate in PHM version denoted by

$$
\lambda_{i}(t)=\alpha \gamma t^{\gamma-1} \exp \left(\theta^{\prime} X_{i}\right)
$$

where $\theta$ is a $p \times 1$ vector of regression parameters and $X_{i}$ is a $1 \times p$ vector of covariates measuring individual characteristics of mortgage loan and its borrower. Thus, given time to default data from $n$ mortgage loans, $D=$ $\left(t_{1}, \ldots, t_{\mathrm{n}}\right)$, the likelihood function of $\alpha, \gamma$ and $\theta$ can be written as,

$$
L(\alpha, \gamma, \theta ; D)=\prod_{i=1}^{n} \alpha \gamma t_{i}^{\gamma-1} \exp \left(\theta^{\prime} X_{i}\right) \exp \left[-\alpha t_{i}^{\gamma} \exp \left(\theta^{\prime} X_{i}\right)\right]
$$

It's noted that the joint posterior distribution $p(\alpha, \gamma, \theta \mid D)$ cannot be obtained analytically. Markov chain Monte Carlo (MCMC) method can be applied to generate posterior and predictive inferences for the variables of interest. In empirical analysis which will be carried out in Section 4, WinBUGS (Spiegelhalter et al., 1996) computing program is used to obtain posterior samples of model parameters. And it is assumed a priori that uncertainties of $\alpha$ and $\gamma$ can be described using gamma distributions as $\alpha \sim \operatorname{Gamma}\left(a_{\alpha}, b_{\alpha}\right)$ and $\gamma \sim \operatorname{Gamma}\left(a_{\gamma}, b_{\gamma}\right)$, with known prior parameters $a_{\alpha}, b_{\alpha}, a_{\gamma}$ and $b_{\gamma}$ A multivariate normal distribution is assigned for $\theta \sim \operatorname{MVN}(\boldsymbol{\mu}, \boldsymbol{W})$ where mean vector $\boldsymbol{\mu}$ and covariance matrix $\boldsymbol{W}$ are known quantities. Furthermore, it is assumed that $\alpha, \gamma$ and $\theta$ are independent of each other.

It is noted that model in (4) can be modified via indexing the scale parameter as $\alpha_{\mathrm{i}}$, to take into account potential heterogeneity in default risk of mortgages which cannot be captured by covariates $X_{\mathrm{i}}$. The model constructed above is similar to those of Merrick et al. (2003) and Soyer and Xu (2010). But we use a simple Weibull PHM format, while Merrick et al. (2003) developed a semiparametric setup and Soyer and Xu (2010) applied generalized gamma and mixture models.

With generated posterior samples $\left\{\alpha^{(g)}, \gamma^{(g)}, \theta^{(g)}\right\}_{g=1}^{G}$ of size $G$, the posterior predictive distribution for time to default of mortgage $j$ with covariates information $X_{\mathrm{j}}$,

$$
f\left(t_{j} \mid D, X_{j}\right)=\int f\left(t_{j} \mid \alpha, \gamma, \theta\right) d P(\alpha, \gamma, \theta \mid D)
$$

can be approximated using Monte Carlo average

$$
f\left(t_{j} \mid D, X_{j}\right) \simeq \frac{1}{G} \sum_{g=1}^{G} f\left(t_{j} \mid \alpha^{g}, \gamma^{g}, \theta^{g}\right)
$$

According to Mazzuchi and Soyer (1995) and Merrick et al. (2003), by setting planned time of conducting loan modification to be $t_{\mathrm{lm}}$ (which is earlier than the loan maturity time), per unit time cost of mortgage $i$ with life length $T_{i}$ can be stated as,

$$
C\left(t_{l m}, T_{i}\right)=\frac{C_{D}}{T_{i}} I\left(T_{i}<t_{l m}\right)+\frac{C_{l m}}{t_{l m}} I\left(T_{i} \geq t_{l m}\right)
$$

where $C_{D}$ is the cost of default brought to lenders and investors, $C_{l m}$ is the cost of conducting preventive loan modification. $I(\cdot)$ is an indicator function which takes value one if the argument is true, otherwise it takes value zero. Therefore, the optimal individual loan modification strategy is to find time $t_{\mathrm{lm}}$ that minimizes the expected $\operatorname{cost} E\left[C\left(t_{\mathrm{lm}}, T_{i}\right)\right]$.

Default $\operatorname{cost} C_{D}$ contains direct costs of modification after the loan becomes delinquent and the cost of foreclosure while the modification practice fails, as well as the indirect costs of increasing default risk due to negative impact on property prices in the community. We consider direct costs only, which consist of the processing fees, loss of interests and principal repayments, legal fees, and property taxes as well as hazard insurance burden transferred to lender, etc. (Ambrose \& Capone, 1996). Precise calculation of the direct costs requires estimate of the probability of mortgage loan ending in foreclosure. Due to unavailability of post delinquent performance data, in our analysis we use historical values reported in extant literature.

Similar to the setup in Merrick et al. (2003), given parameters $\alpha, \gamma$ and $\theta$ in (6), the expected per unit time cost equals

$$
E\left[C\left(t_{l m}, T_{i}\right)\right]=\int E\left[C\left(t_{l m}, T_{i}\right) \mid \alpha, \gamma, \theta\right] p(\alpha, \gamma, \theta \mid D) d \alpha d \gamma d \theta
$$

where,

$$
E\left[C\left(t_{l m}, T_{i}\right) \mid \alpha, \gamma, \theta\right]=\int_{0}^{t_{l m}} \frac{C_{D}}{t_{i}} f\left(t_{i} \mid \alpha, \gamma, \theta\right) d t_{i}+\frac{c_{l m}}{t_{l m}} S\left(t_{l m} \mid \alpha, \gamma, \theta\right)
$$

Based on posterior samples $\left\{\alpha^{(g)}, \gamma^{(g)}, \theta^{(g)}\right\}_{g=1}^{G}$ generated, the expected cost $E\left[C\left(t_{\mathrm{Im}}, T_{i}\right)\right]$ can be calculated 
using Monte Carlo approximation in form of

$$
E\left[C\left(t_{l m}, T_{i}\right)\right] \simeq \frac{1}{G} \sum_{g=1}^{G}\left[\int_{0}^{t_{l m}} \frac{C_{D}}{t_{i}} f\left(t_{i} \mid \alpha^{(g)}, \gamma^{(g)}, \theta^{(g)}\right) d t_{i}+\frac{C_{l m}}{t_{l m}} S\left(t_{l m} \mid \alpha^{(g)}, \gamma^{(g)}, \theta^{(g)}\right)\right]
$$

In addition, it is assumed that after modifying the loan, with either principal forgiveness, interest reduction, term extension, or capitalization of all arrears, etc., the loan is treated as a renewed mortgage contract so the risk of redefault becomes irrelevant in calculating the expected cost in (11). Therefore, the optimal time $t_{l m}{ }^{*}$ to provide preventive loan modification for an individual mortgage can be found by minimizing the expected cost with respect to $t_{l m}$.

\subsection{Preventive Maintenance for a Group of Mortgage Loans}

Individual preventive maintenance strategy requires periodically careful monitor of loan performance. Alternative, for a small pool of high risk mortgage loans, it may be cost effective for lenders to offer loan modifications to all mortgagors. The strategy here is similar to block maintenance strategies considered in reliability literature (see, e.g., Cho \& Parlar. 1991; Mazzuchi \& Soyer, 1995 and 1996; Merrick et al., 2003 and 2005).

Based on the block maintenance strategies developed by Mazzuchi and Soyer (1996) and Merrick et al. (2005), assuming the planned time to conduct group maintenance is $t_{B}$ which is less than the maturity time of the mortgage pool, the cost per unit time can be stated as,

$$
C\left(t_{B}, N\left(t_{B}\right)\right)=\frac{C_{B}\left[N-N\left(t_{B}\right) R(F \mid \text { Def })\right]+C_{A v g . D} N\left(t_{B}\right)}{t_{B}}
$$

where $C_{B}$ is cost per loan of conducting group maintenance, $C_{A v g . D}$ is the average cost brought to the lender by an individual mortgage loan default, $N$ is the initial mortgage pool size, $R(\mathrm{~F} \mid \mathrm{Def})$ is the ratio of defaulted loans ending in the foreclosure and $N\left(t_{B}\right)$ is the number of defaults during time interval $t_{B}$. Thus, the optimal strategy is to find $t_{B}{ }^{*}$ which minimize the expected cost of $C\left(t_{B}, N\left(t_{B}\right)\right)$.

In (12), $C_{B}$ and $C_{A v g . D}$ can be estimated using historical data. For $N\left(t_{B}\right)$, its behavior over time can be described using a nonhomogeneous Poisson process (NHPP) with cumulative intensity function $\Lambda(t)$ (Ross, 2003) stated in a power law format,

$$
\Lambda(t)=E[N(t)]=\alpha t^{\gamma}
$$

where $\alpha, \gamma>0$. The power law model implies that the default intensity decreases (with $\gamma\langle 1$ ) or increases (with $\gamma>$ 1) over time. Besides, effects of covariates on mortgage pool performance can be incorporated using a modulated Poisson process model (MPPM) of Cox (1972) in which the cumulative intensity is denoted by

$$
\Lambda(t, X(t))=\alpha t^{\gamma} \exp \left[\beta^{\prime} X(t)\right]
$$

where $\beta$ is a $p \times 1$ vector of regression parameters and $X$ is a vector of covariates influencing default risk of all mortgage loans in the pool. When $X$ cannot adequately reflects factors influencing default risk, (14) can be modified by indexing parameter $\alpha$ to be $\alpha_{\mathrm{i}}$ 's, which can be assumed to follow conditionally independent lognormal distribution as $\ln \left(\alpha_{i}\right) \sim N\left(\mu_{\alpha}, \tau^{-1}\right)$, or follow a Markov process in form of $\ln \left(\alpha_{i}\right) \sim N\left(\ln \left(\alpha_{i-1}\right), \tau^{-1}\right)$, with common precision parameter $\tau$ follows a gamma density with specified parameters.

According to independent increments property of the NHPPs, given $D=\left\{n_{i}\left[t_{\mathrm{i}-1}, t_{\mathrm{i}}\right] ; i=1, \ldots, T\right\}$, the number of defaults in $T$ intervals of equal length, the likelihood function of $\alpha, \gamma$ and $\theta$ can be written as

$$
L(\alpha, \gamma, \beta ; D)=\prod_{i=1}^{T} \frac{\left(\left[\alpha t_{i}^{\gamma}-\alpha t_{i-1}^{\gamma}\right] \exp \left(\beta^{\prime} X_{i}\right)\right)^{n_{i}}}{n_{i} !} \exp \left\{-\left[\alpha t_{i}^{\gamma}-\alpha t_{i-1}^{\gamma}\right] \exp \left(\beta^{\prime} X_{i}\right)\right\}
$$

where $X_{i}$ is the vector of covariates observed during the $i^{\text {th }}$ interval.

Similar to that in (5), joint posterior distribution $p(\alpha, \gamma, \beta \mid D)$ is not available in any known closed form. The MCMC method can be applied for generating posterior and predictive inferences. Same as in the setup of individual preventive maintenance model, we assign gamma priors for $\alpha$ and $\gamma$ in form of $\alpha \sim \operatorname{Gamma}\left(a_{\alpha}, b_{\alpha}\right)$ and $\gamma \sim \operatorname{Gamma}\left(a_{\gamma}, b_{\gamma}\right)$, with known prior parameters $a_{\alpha}, b_{\alpha}, a_{\gamma}$ and $b_{\gamma}$. A priori, a multivariate normal distribution is assigned for $\beta, \beta \sim \operatorname{MVN}(\boldsymbol{\mu}, \boldsymbol{W})$, where mean vector $\boldsymbol{\mu}$ and covariance matrix $\boldsymbol{W}$ are known quantities. And $\alpha, \gamma$ and $\theta$ are assumed to be independent of each other.

Based on the above setup, once posterior samples $\left\{\alpha^{(g)}, \gamma^{(g)}, \beta^{(g)}\right\}_{g=1}^{G}$ of size $G$ using MCMC algorithm have been generated, expected cost per unit time for group maintenance, 


$$
E\left[C\left(t_{B}, N\left(t_{B}\right)\right)\right]=\int E\left[C\left(t_{B}, N\left(t_{B}\right)\right) \mid \alpha, \gamma, \beta\right] p(\alpha, \gamma, \beta \mid D) d \alpha d \gamma d \beta
$$

can be approximated via Monte Carlo average as

$$
E\left[C\left(t_{B}, N\left(t_{B}\right)\right)\right] \simeq \frac{1}{G} \sum_{g=1}^{G}\left\{\frac{C_{B}\left[N-\alpha^{(g)} t_{B} \gamma^{(g)} \exp \left(\beta^{(g)^{\prime}} X\right) R(F \mid \mathrm{Def})\right]}{t_{B}}+\frac{C_{A v g . D} \alpha^{(g)} t_{B} \gamma^{(g)} \exp \left(\beta^{(g)}{ }^{\prime} X\right)}{t_{B}}\right\}
$$

Therefore, optimal group maintenance time, $t_{B}{ }^{*}$, can be determined by minimizing expected cost of (17) with respect to $t_{B}$.

\section{Empirical Analysis Using Mortgage Default Data}

Data for empirical analysis in this section is from FHA's regional office at Atlanta. It consists of defaulted FRM 30-year mortgage loans originated in 1994 and in 1995. The dataset contains loan endorsement and default dates. It also includes loan amount, interest rate, borrower's effective household income, loan to value (LTV) ratio range, borrower's marital status and age, all of which are recorded at loan origination time.

To illustrate the effectiveness of individual preventive maintenance model, we randomly select 400 samples from 1994 cohort of defaulted loans. The data is analyzed using Weibull PHM model listed in (5). Posterior samples of parameters in the model are then used to provide posterior predictive estimates of default time for randomly selected mortgage loans from 1995 cohort data.

Monthly counts of mortgage defaults from 1994 cohort loans are used to generate posterior samples of parameters for group maintenance model, which are used for obtaining posterior predictive inferences of default counts for 1995 cohort mortgage pool. The expected per unit time cost of conducting group preventive maintenance can then be computed based on those posterior predictions.

\subsection{Analysis of Preventive Maintenance of Individual Mortgage Loan}

WinBUGS program of Spiegelhalter et al. (1996) is applied for computing and generating posterior samples of model parameters. In our analysis, all parameters are assigned proper but diffused priors. Both $\alpha$ and $\gamma$ are assumed to follow a gamma distribution with scale and shape parameters of $(0.01,0.01)$. Covariate coefficients are assumed to have independent normal priors with zero mean and 0.01 precision value. In running WinBUGS program, we exclude 10,000 burn-in samples and collect 10,000 posterior samples after thinning by 100 . There is no convergence issue in the posterior samples obtained, according to diagnostics using the Bayesian Output Analysis (BOA) program of Smith (2007).

Statistics of posterior samples for model parameters are presented in Table 1 below, in which "St.Dev." stands for standard deviation and $2.50 \%$ and $97.5 \%$ columns provide corresponding percentiles of the sample data. From the table, we note that effects of mortgage interest rate and loan size on default risk are consistent with what are expected, as higher mortgage rate and loan amount result in heavier burden on borrower's ability to repay the mortgage loan. Effects from other covariates are not clear, due to possible reason that default risk are more likely to be influenced by changes of these covariates, instead of their initial levels.

The posterior samples are then applied to a randomly selected high risk (e.g., EPD loans) 1995 cohort mortgage loan, to obtain the posterior inferences of time to default. In our analysis, the unit of time is set to be one month, as mortgagors are required to pay for principal and interest on a monthly basis. The 1995 loan selected was originated in Jan. 1995. Other information given from the original source stated that at time of mortgage contract initiation, the borrower was 38 years old and married, with annual household income of $\$ 43,008$. The mortgage interest rate charged was $7.5 \%$ fixed 30 -year rate, and the loan amount was $\$ 100,116$, with an LTV ratio between $97 \%$ and $98 \%$. The borrower defaulted in mortgage payment after 26 months.

Table 1. Statistics of posterior samples of Weibull PHM parameters

\begin{tabular}{cccccc}
\hline Parameter & Mean & St. Dev. & $2.50 \%$ & Median & $97.50 \%$ \\
\hline$\alpha$ & 0.00062 & 0.00039 & 0.00017 & 0.00053 & 0.00161 \\
$\gamma$ & 1.59700 & 0.06229 & 1.47800 & 1.59600 & 1.72000 \\
$\theta_{\text {mortgage rate }}$ & 1.63300 & 0.50110 & 0.65060 & 1.63000 & 2.62900 \\
$\theta_{\text {mortgage amount }}$ & 0.95840 & 0.23050 & 0.50840 & 0.95680 & 1.41400 \\
$\theta_{\text {income }}$ & -0.51560 & 0.47630 & -1.49100 & -0.49800 & 0.38370 \\
$\theta_{\text {marital status }}$ & 0.10420 & 0.52700 & -0.94450 & 0.10280 & 1.12900 \\
$\theta_{\text {borrower's age }}$ & -0.87580 & 0.49460 & -1.86500 & -0.86710 & 0.08836 \\
$\theta_{\text {LTV }}$ & 0.02772 & 0.45370 & -0.85500 & 0.02999 & 0.91590 \\
\hline
\end{tabular}


Assuming it is now at the end of first month of the mortgage duration, the lender needs to decide when to provide preventive loan modification. Based on individual preventive maintenance model, we need to determine relevant costs. As discussed in Section 3.1, we do not have access to the proprietary data of mortgage loan lenders, therefore we use hypothesized values based on the extant literature, for illustration purpose of the model. Considering loan servicers often wait for more than one month before carrying out loan modification process, according to findings of Stegman et al. (2007), we assume that the probability a modified loan reaching foreclosure equals 0.3. Stegman et al. (2007) further reported that the loss of defaulted loan was in the range between $30 \%$ and $40 \%$ of original loan amount, compared to 35\% of loss rate based on HUD (2005). White (2009) declared that on average loss of foreclosure is around 55\% of unpaid principal amount. In our analysis we use the later percentage, considering that the lender can collect proportions of the principal and interest payments after certain months. For a FRM 30-year mortgage loan with initial principal amount $M$ and monthly interest rate $i$, unpaid principal amount $M(t)$ at the end of month $t$ is calculated as,

$$
M(t)=M \times \frac{(1+i)^{360}-(1+i)^{t}}{(1+i)^{360}-1}
$$

White (2009) found that the median cost of modification after mortgage loan being delinquent was equal to $\$ 1,857$. He further pointed out that there was a $\$ 500$ service fee, which will be used as the estimate of cost for providing preventive loan modification. Given costs information, expected monthly cost of conducting preventive loan modification can be calculated using formula in (11). Figure 1 below plots expected per month cost against number of months before conducting individual preventive loan modification. From the figure, it can be found that the optimal time for preventive practice is during the $13^{\text {th }}$ month. The actual mortgage loan defaulted in the $27^{\text {th }}$ month with $\$ 99,174$ unpaid principal balance. Thus, the cost saving effect of preventive maintenance model is validated, given significant costs brought by the default and foreclosure. It also benefits the mortgagor with more affordable payment plan which lower the risk of future default.

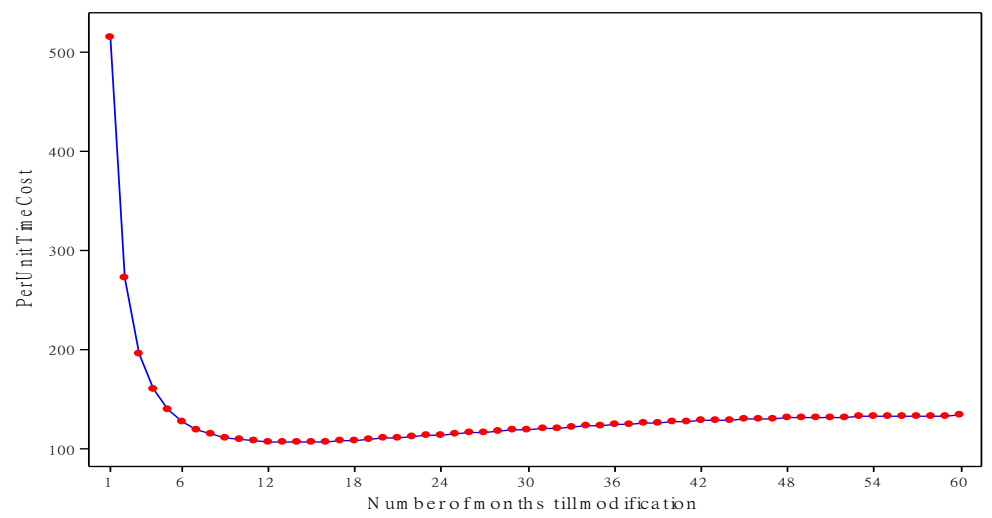

Figure 1. Expected monthly cost of individual preventive maintenance policy

\subsection{Analysis of Group Preventive Maintenance}

To calculate the cost of conducting group maintenance, we randomly selected 8,000 mortgage loans from 1994 FRM 30-year mortgage cohort, which are applied to the MPPM model for generating posterior samples of all parameters. Aggregate default counts are obtained by accumulating monthly default occurrences of loans selected in the sample. Covariates included in the analysis are periodic Conventional Mortgage Home Price Index (CMHPI) and Federal Cost of Funds Index (COFI) provided by Freddie Mac, as well as Homeowner Mortgage Financial Obligations Ratio (FOR Mortgage) from The Federal Reserve Board and the U.S. Census South regional unemployment rate (Unemployment).

Using WinBUGS program, we assign proper but diffused priors for $\alpha, \gamma$ and $\beta$, as those in previous Weibull PHM model. Diagnostics from BOA analysis do not reveal any convergence problem. Table 2 below presents posterior summaries of model parameters. We note that housing price has negative impact on mortgage default, as housing properties increase in their market value, mortgage borrowers become more reluctant to default. As what are expected, FOR Mortgage ratio and unemployment rate, two factors influencing borrowers' ability to pay for mortgage loans, have positive impact on the default risk. The interest rate (COFI) has an opposite influence on the default occurrence comparing to what is expected. This may be the result that increase in the rate relates to increase in other living expenses of mortgage borrowers. 
Table 2. Posterior statistics of MPPM parameters

\begin{tabular}{cccccc}
\hline Parameter & Mean & St. Dev. & $2.50 \%$ & Median & $97.50 \%$ \\
\hline$\alpha$ & 0.001 & 0.000 & 0.000 & 0.000 & 0.001 \\
$\gamma$ & 2.126 & 0.037 & 2.054 & 2.126 & 2.201 \\
$\beta_{\text {CMHPI }}$ & -40.320 & 2.056 & -44.360 & -40.330 & -36.300 \\
$\beta_{\text {COFI }}$ & 3.931 & 0.427 & 3.117 & 3.922 & 4.803 \\
$\beta_{\text {FOR Mortgage }}$ & 9.612 & 1.134 & 7.617 & 9.579 & 11.960 \\
$\beta_{\text {Unemployment }}$ & 4.426 & 0.587 & 3.274 & 4.432 & 5.549 \\
\hline
\end{tabular}

The posterior samples are then used to obtain the expected per unit time cost in (17) for an assumed mortgage loan pool which consists of 8,000 randomly selected loans from 1995 cohort data. It is assumed that current time is in the first month of 1995 and the loan lender needs to find the optimal time of conducting group modifications. Per loan cost of group preventive modification $C_{B}$, is set to equal to $\$ 500$, same as that in the analysis of individual preventive maintenance model. In real analysis, ratio of post-delinquent foreclosure $R(\mathrm{~F} \mid \mathrm{Def})$ and future covariates values require additional statistical models to provide reliable estimates. For illustration purpose, in our analysis hereafter, we assumed that $R(\mathrm{~F} \mid \mathrm{Def})$ equals 0.3 , based on value given by Stegman et al. (2007). Covariates' values are assumed to be kept the same as those observed in Jan. 1995. Average cost of default $C_{\text {Avg. } .}$ is calculated based on mean value $(\$ 62,782)$ of all loan amounts in the mortgage pool, 0.35 loss rate based on HUD (2005), 0.3 post-delinquent foreclosure ratio and $\$ 1,857$ post-delinquent modification cost given by White (2009).

Figure 2 plots expected cost per unit time of conducting group preventive maintenance policy against number of months till group modifications. Based on the plot, it is clear that for the mortgage pool under study, the optimal strategy is to modify all mortgage loans remaining in the pool during the $15^{\text {th }}$ month, which is in March 1996 based on the assumption.

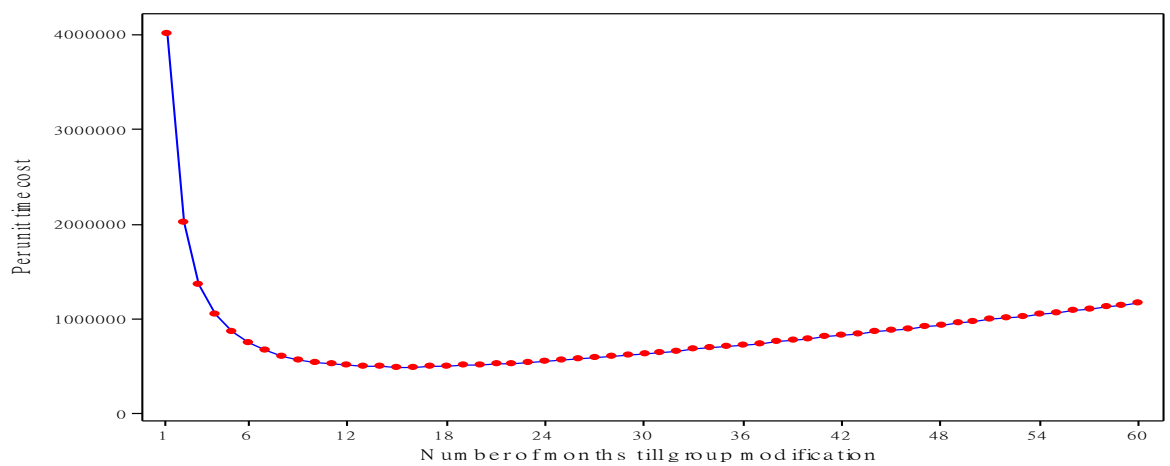

Figure 2. Expected per month cost of group preventive maintenance policy

\section{Conclusions}

In this paper, we presented preventive maintenance models for controlling default risks of risky mortgage loans. Compared to common practice of providing post-default loan modifications in the mortgage market, we propose proactive practice by carrying out modifications even before mortgage borrowers default in the loan payment.

Two types of preventive maintenance models were constructed to provide cost management methods in dealing with default risk of individual mortgage loan and a pool of mortgage loans characterized with low-income borrowers who have high perceived probabilities of encountering affordability difficulties. The Weibull PHM and MPPM models were applied to obtain posterior predictive inferences for measuring corresponding per unit time costs of conducting individual and group preventive loan modifications.

Analysis using real mortgage default data demonstrated cost effectiveness for lenders to conduct preventive maintenances. There also exist externality effects based on the proposed practice for mortgagors to better maintain homeownership and for policy makers to maintain market stability.

Future research can extend this study by incorporating loan performance especially the post-default loan performance data, to provide a more thorough decision-making framework of new models proposed. New statistical methods, such as semiparametric models of Merrick et al. (2003), can be applied to measure time to default of individual mortgage loan and counting process of default occurrence of a mortgage pool. 


\section{References}

Agarwal, S., Amromin, G., Ben-David, I., Chomsisengphet, S., \& Evanoff, D. D. (2010). Market-Based loss mitigation practices for troubled mortgages following the financial crisis. Federal Reserve Bank of Chicago Working Paper. https://doi.org/10.2139/ssrn.1690627

Agarwal, S., Amromin, G., Ben-David, I., Chomsisengphet, S., \& Evanoff, D. D. (2011). The role of securitization in mortgage renegotiation. Journal of Financial Economics, 102, 559-578. https://doi.org/10.1016/j.jfineco.2011.07.005

Ambrose, B. W., \& Buttimer, Jr., R. J. (2000). Embedded options in the mortgage contract. Journal of Real Estate Finance and Economics, 21(2), 95-111. https://doi.org/10.1023/A:1007819408669

Ambrose, B. W., \& Capone, Jr., C. A. (1996). Cost Benefit Analysis of Single-Family Foreclosure Alternatives. Journal of Real Estate Finance and Economics, 13, 105-20. https://doi.org/10.1007 /BF00154051

Ambrose, B. W., \& Capone, Jr., C. A. (1998). Modeling the Conditional Probability of Foreclosure in the Context of Single-Family Mortgage Default Resolutions. Real Estate Economics, 26(3), 391-429. https://doi.org/10.1111/1540-6229.00751

Anderson, S., Kogler, B., \& Kim, D. (2012). Loan modification performance: A multivariate review approach. Journal of Structured Finance, 18(2), 33-49. https://doi.org/10.3905/jsf.2012.18.2.033

Bhattacharya, A., Wilson, S. P., \& Soyer, R. (2019). A Bayesian approach to modeling mortgage default and prepayment. European Journal of Operational Research, 274(3), 1112-1124. https://doi.org/10.1016/j.ejor.2018.10.047

Campodonico, S., \& Singpurwalla, N. D. (1995). Inference and Predictions for Poisson Point Processes Incorporating Expert Knowledge. Journal of the American Statistical Association, 90, 220-226. https://doi.org/10.1080/01621459.1995.10476505

Capone, Jr., C. A. (2002). Research into mortgage default and affordable housing: A primer. Prepared for the LISC Center for Home Ownership Summit 2001, March 2002. Retrieved from http://www.lisc.org/resources/2002/05/affordable_793.shtml?Affordable+Housing

Capone, Jr., C. A., \& Metz, A. (2003). Mortgage Default and Default Resolutions: Their Impact on Communities. Federal Reserve Bank of Chicago, Conference on Sustainable Community Development, Washington, DC, March 27, 2003. Retrieved from https://www.chicagofed.org/digital_assets/others/events/2003/seeds_of_ growth/2003_conf_paper_session2_capone.pdf

Castro, I. T. (2009). A Model of Imperfect Preventive Maintenance with Dependent Failure Modes. European Journal of Operational Research, 196(1), 217-224. https://doi.org/10.1016/j.ejor.2008.02.042

Cho, D. I., \& Parlar, M. (1991). A Survey of Maintenance Models for Multi-Unit Systems. European Journal of Operational Research, 51, 1-23. https://doi.org/10.1016/0377-2217(91)90141-H

Cox, D. R. (1972). Regression Models and Life Tables. Journal of Royal Statistical Society, Ser. B, 34(2), 187-220. https://doi.org/10.1111/j.2517-6161.1972.tb00899.x

Cutts, A. C., \& Merrill, W. A. (2008). Interventions in Mortgage Default: Policies and Practices to Prevent Home Loss and Lower Costs. Freddie Mac Working Paper, \#08-01. Retrieved from http://www.clevelandfed.org/Our_Region/Community_Development/pdf/interventions_in_mortgage_defaul t_Frank.pdf

Ding, L., Quercia, R. G., \& Ratcliffe, J. (2008). Post-purchase counseling and default resolutions among lowand moderate-income borrowers. The Journal of Real Estate Research, 30(3), 315-344. https://doi.org/10.1080/10835547.2008.12091223

Engelstad, R. (1991). Foreclosure Prevention and Loss Mitigation. Memorandum to Seller-Servicers. Fannie Mae Corporation, May 17th, 1991.

Gardner, M. J., \& Mills, D. L. (1989). Evaluating the Likelihood of Default on Delinquent Loans. Financial Management, 18(4), 55-63. https://doi.org/10.2307/3665797

Gerardi, K., \& Li, W. (2010). Mortgage foreclosure prevention efforts. Economic Review. Federal Reserve Bank of Atlanta, Atlanta, GA, Vol. 95. Retrieved from https://www.econstor.eu /handle/10419/57666

Hirad, A., \& Zorn, P. M. (2001). A Little Knowledge Is a Good Thing: Empirical Evidence of the Effectiveness of Pre-Purchase Homeownership Counseling. Low-Income Homeownership Working Paper Series, Joint 
Center for Housing Studies, Harvard University. Retrieved from http://www.jchs.harvard.edu/sites/jchs.harvard.edu/files/liho01-4.pdf

HUD. (2000). Mortgagee Letter 00-05: Loss Mitigation Program - Comprehensive Clarification of Policy and Notice of Procedural Changes. U.S. Department of Housing and Urban Development (Washington, D.C, Jan. 19th, 2000), 1-45.

HUD. (2005). Actuarial Review of the Mutual Mortgage Insurance Fund FY 2005. Retrieved from http://portal.hud.gov/hudportal/HUD?src=/program_offices/housing/rmra/oe/rpts/actr/2005actr

Lambrecht, B., Perraudin, W., \& Satchell, S. (1997). Time to default in the UK mortgage market. Economic Modelling, 14(4), 485-499. https://doi.org/10.1016/S0264-9993(97)00003-5

Lipschutz, R. (2000). Federal Housing Administration Sees Progress in Loss Mitigation Efforts. National Mortgage News, 24(27), 36.

Lynn, N. J. (2004). The price of failure. In R. Soyer, T. A. Mazzuchi, \& N. D. Singpurwalla (Eds.), Mathematical Reliability: An Expository Perspective (pp. 303-316). Kluwer: Norwell, MA. https://doi.org/10.1007/978-1-4419-9021-1_16

Mazzuchi, T. A., \& Soyer, R. (1996). A Bayesian Perspective on Some Replacement Strategies. Reliability Engineering and System Safety, 51(3), 295-303. https://doi.org/10.1016/0951-8320(95)00077-1

Mazzuchi, T. A., \& Soyer, R. (1996). Adaptive Bayesian Replacement Strategies. In J. M. Bernado, J. O. Berger, A. P. Dawid, \& A. F. Smith (Eds.), Bayesian Statistics (vol. 5, pp. 667-674). Oxford University Press.

Merrick, J. R. W., Soyer, R., \& Mazzuchi, T. A. (2003). A Bayesian Semiparametric Analysis of the Reliability and Maintenance of Machine Tools. Technometrics, 45(1), 58-69. https://doi.org/10.1198/004017002188618707

Merrick, J. R. W., Soyer, R., \& Mazzuchi, T. A. (2005). Are Maintenance Practices for Railroad Tracks Effective? Journal of the American Statistics Association, 100(469), 17-25. https://doi.org/10.1198/016214504000002104

Mulligan, C. B. (2010). Foreclosures, enforcement, and collections under the federal mortgage modification guidelines. NBER Working Paper, \# 15777. https://doi.org/10.3386/w15777

Ross, S. M. (2003). Introduction to Probability Models (8th ed.). Academic Press.

Singpurwalla, N. D. (2007). Reliability and survival in financial risk. In V. J. Nair (Ed.), Advances in Statistical Modeling and Inference - Essays in Honor of Kjell Doksum (pp. 93-114). World Scientific: Singapore. https://doi.org/10.1142/9789812708298_0005

Smith, B. J. (2007). Bayesian output analysis (BOA) user manual (version 1.1.6). Department of Biostatistics, College of Public Health, University of Iowa.

Soyer, R., \& Xu, F. (2010). Assessment of mortgage default risk via Bayesian reliability models. Applied Stochastic Models in Business and Industry, 26(3), 308-330. https://doi.org/10.1002/asmb.849

Spiegelhalter, D., Thomas, A., Best, N., \& Gilks, W. (1996). Bayesian Inference Using Gibbs Sampling Manual (version ii). MRC Biostatistics Unit, Cambridge University.

Stegman, M. A., Quercia, R. G., Ratcliffe, J., Ding, L., \& Davis, W. R. (2007). Preventive servicing is good for business and affordable homeownership policy. Housing Policy Debate, 18(2), 243-278. https://doi.org/10.1080/10511482.2007.9521600

Stowe, A. M. (1997). Servicing FHA single-family loans. Mortgage Banking, 57(9), 91-97.

White, A. M. (2009). Deleveraging the American homeowner: the failure of 2008 voluntary mortgage contract modifications. Connecticut Law Review, 41(4), 1107-1131.

Wu, S., \& Zuo, M. J. (2010). Linear and Nonlinear Preventive Maintenance Models. IEEE Transaction on Reliability, 59(1), 242-249. https://doi.org/10.1109/TR.2010.2041972

\section{Copyrights}

Copyright for this article is retained by the author(s), with first publication rights granted to the journal.

This is an open-access article distributed under the terms and conditions of the Creative Commons Attribution license (http://creativecommons.org/licenses/by/4.0/). 